\title{
Physiological Role of Exogenous Spermine in Wheat (Triticum aestivum em. Thell) under Salinity
}

\author{
Midathala Raghavendra ${ }^{1 *}$, Dommalapati Sudhakara Rao', \\ Shashi Madan ${ }^{1}$ and Renu Munjal ${ }^{2}$
}

${ }^{1}$ Department of Biochemistry, ${ }^{2}$ Department of Botany and Plant Physiology, CCS Haryana Agricultural University, Hisar- 125004 (Haryana), India

*Corresponding author

\section{A B S T R A C T}

\section{Keywords}

Wheat, Exogenous

Spermine,

Triticum aestivum

Article Info

Accepted:

10 August 2020

Available Online:

10 September 2020
The elevated concentration of salts in soils impact plant growth and development by disturbing the capacity of roots to extract water and high levels of salts within the plant supress the physiological and biochemical processes such as nutrient uptake and assimilation. Salinity induced wheat leaves were analysed for various physiological parameters viz. relative water content, leaf membrane injury, osmotic potential and chlorophyll fluorescence at five days after treatment of spermine at $1.0 \mathrm{mM}$ concentration. Spermine treatment showed higher relative water content and improved efficiency of photosystem II $(F v / F m)$ indicating increase water retention capacity in control and salt stressed condition. Further, spermine treatment alleviated the salinity induced leaf membrane injury with marked decrease in ion leakage and played protective role.

\section{Introduction}

Wheat and rice are two major cereal crops that occupy about $50-55 \%$ of the total cropped area of India. Wheat is consumed in various forms by more than one thousand million populations and provides more than 50 percent of human energy and protein needs. Wheat is the most widely cultivated food crop and well adapted to grow in semi-arid regions. Salinity is the main factor impeding sustainable crop production, especially in irrigated arid and semi-arid regions of the world, where the rainfall is too low to prevent accumulations of ions in the soil and where irrigation is the cause of secondary salinization (Calanca, 2017). Salt stress is one of the major environmental constraints affecting and limiting the crop productivity and quality of economically important crops.

Plants growing in saline media may reduce internal water deficits by the absorption of inorganic ions and the synthesis of organic solutes for osmotic adjustment (Kafi et al., 2003). Inorganic ions are accumulated in the vacuole and organic osmolytes in the cytoplasm to balance vacuolar osmotic potential (Mansour, 2000). 
Salinity induces accumulation of a range of nitrogenous compounds, the most frequent being amino acids, amides, proteins, ammonium quaternary compounds and polyamines. These compounds functions in osmotic adjustment, cellular macromolecule protection, nitrogen storage, cellular $\mathrm{pH}$ maintenance, a decrease of cellular toxicity and elimination of free radicals (Zapata et al., 2008).

Application of exogenous polyamines also have been reported, could alleviate salinityinduced damages in rice (Roychoudhury et al., 2011), citrus (Shi et al., 2010), mung bean (Nahar et al., 2016), Kentucky grass (Puyang et al., 2016) and cucumber (Sang et al., 2016).Salt stress along with osmotic stress influences the photosynthesis, water relations, ion homeostasis, yield component, senescence, growth and development of crop plants. As a result, there is a decrease in dry mass, chlorophyll content and soluble proteins which are reflected in qualitative and quantitative grain yield and yield components (Anjum et al., 2008). Tolerance to abiotic stresses is very complex due to intricate interactions between stress factors and various molecular, biochemical, agronomic and physiological phenomenon affecting plant growth and development. To present work is planned to understand the physiological functions of spermine in wheat under saline stress and their responses.

\section{Materials and Methods}

The present experiments were conducted in the Chaudhary Charan Singh Haryana Agricultural University, Hisar. The caryopses of the wheat cultivars (Triticum aestivum L.) DBW 88 and KRL 210 differing in tolerance to salinity were obtained from Wheat and Barley Section, Department of Genetics and Plant Breeding, CCS HAU, Hisar. Seeds of wheat varieties were surface sterilized and grown in earthen pots lined with polyethylene bags filled with $6 \mathrm{~kg}$ dune sand in a screen house under naturally lit conditions. The nutrient solution was used to irrigate the soil supplemented with nutrients in the form of $\mathrm{N}$, $\mathrm{P}$ and $\mathrm{K}$ in the ratio of 10:3:3.

Wheat plants were grown at two levels of salinity ( 8 and $12 \mathrm{dSm}^{-1}$ ) and control. Artificial saline waters of 8 and $12 \mathrm{dSm}^{-1}$ levels were prepared for irrigation of pots by maintaining $\mathrm{Na}: \mathrm{Ca}+\mathrm{Mg}$ ratio as $1: 1 ; \mathrm{Ca}: \mathrm{Mg}$ as 1:3 and that of $\mathrm{Cl}: \mathrm{SO}_{4}$ as 7:3. Plants were irrigated with distilled water to maintain the salinity levels. Spermine at $1.0 \mathrm{mM}$ concentration was sprayed over the plants at 21 days after sowing. Plants were tagged at the time of application of spermine and leaf samples were analysed for physiological traits on $5^{\text {th }}$ day after the spermine treatment.

\section{Relative water content}

Relative water content was measured by the method of Barrs and Weatherley (1962) using the following formula.

Relative water content $=\frac{\text { Fresh weight }- \text { Dry weight }}{\text { Fully turgid weight }- \text { Dry weight }} \times 100$

Turgid mass was determined after saturation of leaf blades in distilled water in sealed glass tubes for $6 \mathrm{~h}$ at room temperature followed by overnight storage at $5^{\circ} \mathrm{C}$. The dry weight was determined after $48 \mathrm{~h}$ at $75^{\circ} \mathrm{C}$.

\section{Leaf membrane injury}

Leaf membrane injury in terms of relative stress injury was measured by Sullivan and Ross, 1979 by using the following formula.

Membrane Injury $=\frac{\mathrm{EC} 1}{\mathrm{EC} 2} \times 100$

The EC1 was measured after soaking the 200 mg leaf segment in $8 \mathrm{ml}$ deionized water at 
$27^{0} \mathrm{C}$ for $5 \mathrm{~h}$ and EC2 was measured after the same sample was kept in boiling water bath at $100^{\circ} \mathrm{C}$ for $30 \mathrm{~min}$. The membrane injury index was calculated as follows:

\section{Osmotic potential}

The osmotic potential of the leaf was measured with a psychrometric technique using VAPRO 5520 vapor pressure osmometer (Wescor INC., Lorganan, Utah, USA) as described by Morgan, 1980. The excised leaf was sealed in Eppendorf tube and quickly frozen at $-20{ }^{0} \mathrm{C}$ and the sap was collected after thawing for $60 \mathrm{~min}$ at $25^{\circ} \mathrm{C}$. About $10 \mu \mathrm{l}$ of sap is used to record the readings of osmometer in $\mathrm{mmol} \mathrm{kg} \mathrm{kg}^{-1}$ were expressed in MPa.

\section{Chlorophyll fluorescence}

The chlorophyll fluorescence was measured by method of Zribi et al., (2009), where measurements of $F_{v} / F_{m}$ were taken from on the surface of flag leaf using a portable handy analyser (Hansatech, UK). The data was analysed, which provides parameters indicating the efficiency of photosystem II.

\section{Results and Discussion}

The mean relative water content (RWC) decreased with increase in the salinity at 21 DAS (from $86.1 \%$ in control to $68.0,64.6 \%$ at $8 \mathrm{dSm}^{-1}$ and $12 \mathrm{dSm}^{-1}$ respectively). Spermine treatment of $1.0 \mathrm{mM}$ concentration showed higher values for RWC in stressed leaves $\left(75.4\right.$ and $76.2 \%$ at $8 \mathrm{dSm}^{-1}$ and 12 $\mathrm{dSm}^{-1}$ respectively). RWC in KRL 210 was found higher when compared with DBW 88 (Fig. 1). Leaf membrane injury in terms of relative stress injury was measured as percent proportions of ion leakage into the external aqueous medium to the total ion concentration of the stressed tissue as measured by the EC of the external medium. There was a progressive increase in the mean leaf membrane injury with increasing levels of salinity i.e., form $37.2 \%$ (control) to $40.0 \%$ $\left(8 \mathrm{dSm}^{-1}\right)$ and $50.3 \%\left(12 \mathrm{dSm}^{-1}\right)$ at $21 \mathrm{DAS}$ (Fig. 2). The application of spermine gradually decreased the leaf membrane injury in both the cultivars DBW88 and KRL 210. Maximum leaf membrane injury was found in DBW $88(55.9 \%)$ at $12 \mathrm{dSm}^{-1}$ without spermine treatment and minimum was recorded in KRL 210 with spermine treatment in control $(35.7 \%)$.

Fig.1 Effect of spermine at 21 DAS on relative water content in wheat flag leaf under salt stress

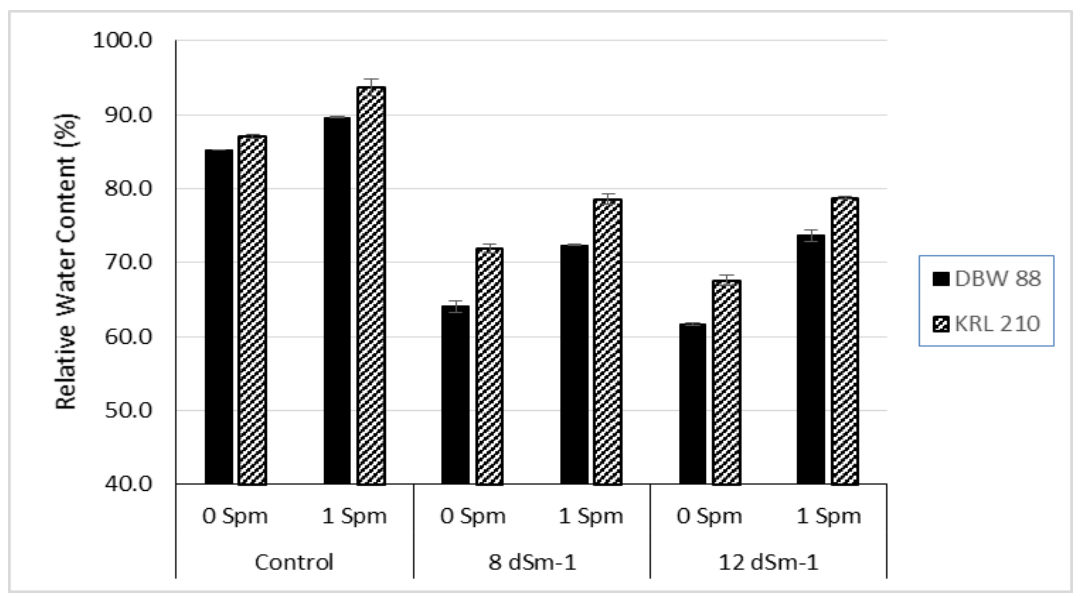


Fig.2 Effect of spermine at 21 DAS on leaf membrane injury in wheat flag leaf under salt stress

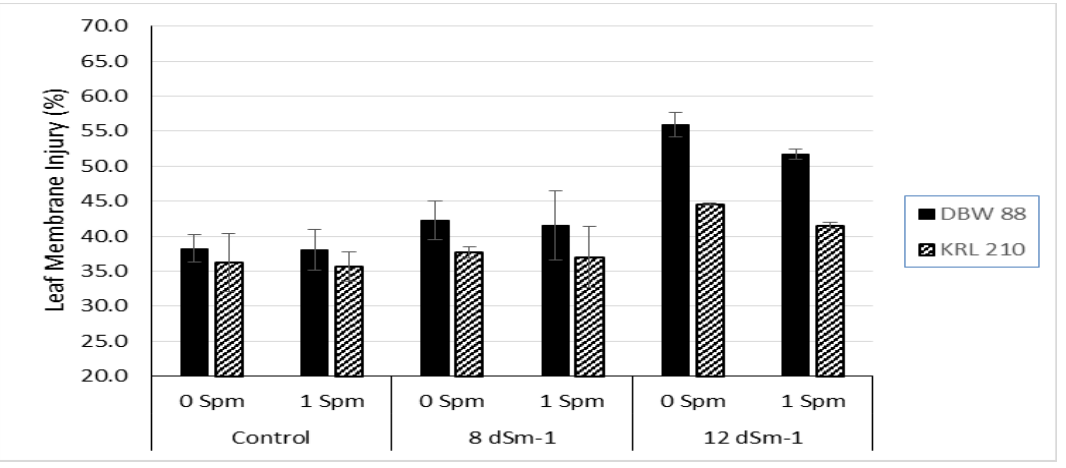

Fig.3 Effect of spermine at 21 DAS on osmotic potential in wheat flag leaf under salt stress

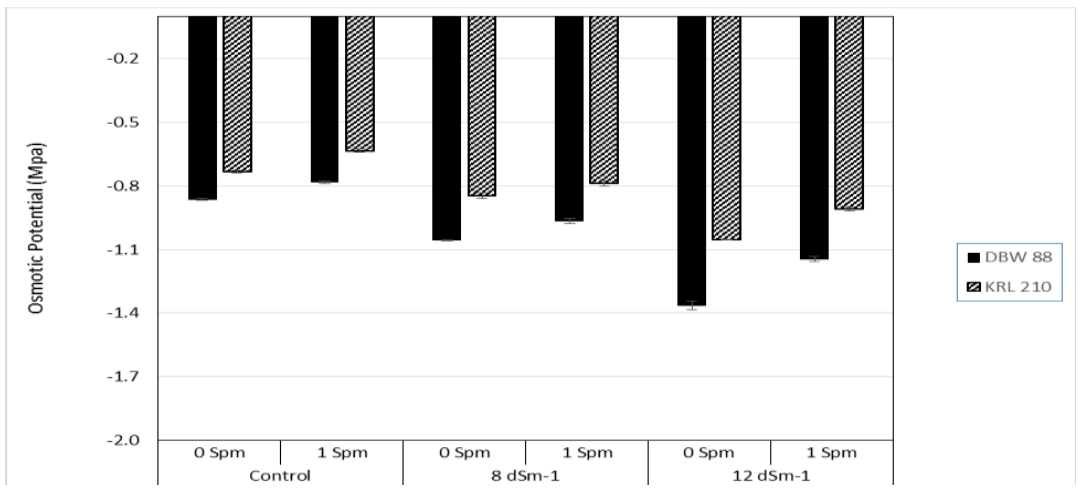

Fig.4 Effect of spermine at 21 DAS on chlorophyll fluorescence in wheat flag leaf under salt stress

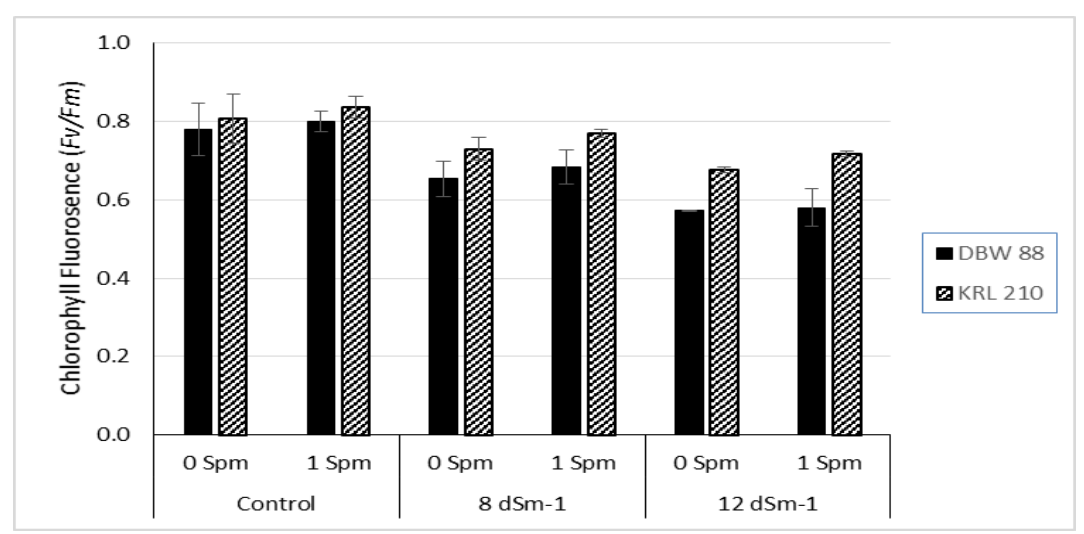

The osmotic potential in wheat leaves decreased (more negative) by the influence of salinity stress at 21 DAS (Fig. 3). The highest mean osmotic potential was obtained in plants treated with spermine in control $(-0.71 \mathrm{MPa})$. The saline treatment decreased the osmotic potential in both DBW 88 and KRL 210 but was more negative in DBW 88 under 12

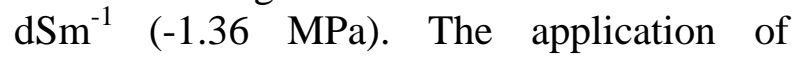
spermine in control and salt stressed plants maintained higher levels of osmotic potential in all the varieties. The maximum 
photochemical efficiency of photosystem II $(F v / F m)$ in wheat plants exposed to various levels of salinity treatments at 21 DAS is represented (Fig. 4). The mean values of $\mathrm{Fv} / \mathrm{Fm}$ was reduced under salt stress from 0.794 to $0.692,0.624$ in 8 and $12 \mathrm{dSm}^{-1}$ respectively. The maximum efficiency of photosystem II was observed in KRL 210 treated with spermine under control conditions and more damage in photosystem II under salt stress was measured in DBW 88 at $12 \mathrm{dSm}^{-1}(F v / F m=0.573)$. Spermine application was found effevtive to increase the $F v / F m$ values when compared with nonspermine under salt stressed wheat varieties.

The relative water content of leaves is regarded as an important indicator of plant physiological activities and a better measure of plant water status. In this study, KRL 210 was found to maintain its RWC relatively higher than DBW 88 (Fig. 1). However, RWC in leaves decreased with increasing levels of salinity and more reduction in RWC was observed in DBW 88. Results on the decline in RWC with salt stress are in accordance with those of rice (Khan and Panda, 2008) and maize (Rohanipoor et al., 2013). Further, Nahar et al., (2016) also showed that exogenous PAs application to salt-stressed mung bean resulted in an increase in leaf RWC. The increase in the leaf membrane injury can disrupt water, ion, and organic solute movement across plant membranes, thus affecting carbon production, transport and accumulation (Mohammed and Tarpley, 2010). The leaf membrane injury increased with increasing levels of salinity and pronounced more in salt sensitive varieties i.e., DBW 88 as compared with tolerant varieties KRL 210 (Fig. 2). However, Spm treated leaves maintained lower levels of leaf membrane injury when compared with untreated leaves. Similarly, polyamines application alleviated drought effects by substantially reducing the membrane permeability (Farooq et al., 2009). The decrease in the plant growth and development under salinity is explained by the decrease of osmotic potential in plant cells due to increasing salt concentration in the soil and consequently decreasing water potential (Akça and Samsunlu, 2012). As is evident from the results obtained during the present investigation, the osmotic potential of wheat leaves decreased (became more negative) by the influence of salinity. Leaf osmotic potential was more negative in DBW 88 than KRL 210. The reduction in osmotic potential in salt-stressed plants mainly occurs due to the accumulation of inorganic ions (Hasegawa et al., 2000) limiting the availability of water to plants. Farooq et al., (2009) showed that exogenously applied PAs substantially improved the drought-induced decrease of RWC and osmotic potential in rice. Results presented in Fig. 4 show that the maximum photochemical efficiency of photosystem II $\left(F_{v} / F_{m}\right)$ in wheat plants decreased with increasing levels of salinity at 21 DAS. Similarly, a decrease in maximum photochemical efficiency of photosystem II under salt stress was reported in wheat cultivars (Khan et al., 2012). However, higher values for $F_{\downarrow} / F_{m}$ was maintained in KRL 210 under salinity when compared with salt susceptible varieties.

The results obtained in the present investigation indicate that salt tolerance in KRL 210 may be due to improved RWC, Leaf membrane injury, osmotic potential and chlorophyll fluorescence. In addition, the exogenous spermine treatment may be associated with the capacity to tolerate under salt stress in wheat.

\section{References}

Akça, Y. and Samsunlu, E. (2012). The effect of salt stress on growth, chlorophyll content, proline and nutrient 
accumulation and $\mathrm{K}^{+} / \mathrm{Na}^{+}$ratio in walnut. Pakistan Journal of Botany, 44, 1513-1520.

Anjum, F., Wahid, A., Javed, F. and Arshad, M. (2008) Influence of foliar applied thiourea on flag leaf gas exchange and yield parameters of bread wheat (Triticum aestivum) cultivars under salinity and heat stresses. International Journal of Agriculture and Biology, 10, 619-626.

Barrs, H. and Weatherley, P. (1962). A reexamination of the relative turgidity technique for estimating water deficits in leaves. Australian Journal of Biological Sciences, 15, 413-428.

Calanca, P.P. (2017). Effects of Abiotic Stress in Crop Production. Quantification of Climate Variability, Adaptation and Mitigation for Agricultural Sustainability (eds M. Ahmed, C.O. Stockle), pp. 165-180. Springer.

Farooq, M., Wahid, A. and Lee, D.J. (2009). Exogenously applied polyamines increase drought tolerance of rice by improving leaf water status, photosynthesis and membrane properties. Acta Physiologiae Plantarum, 31, 937-945.

Hasegawa, P.M., Bressan, R.A., Zhu, J.-K. and Bohnert, H.J. (2000). Plant cellular and molecular responses to high salinity. Annual Review of Plant Biology, 51, 463-499.

Kafi, M., Stewart, W. and Borland, A. (2003) Carbohydrate and Proline Contents in Leaves, Roots, and Apices of SaltTolerant and Salt-Sensitive Wheat Cultivars. Russian Journal of Plant Physiology, 50, 155-162

Khan, M. and Panda, S. (2008) Alterations in root lipid peroxidation and antioxidative responses in two rice cultivars under $\mathrm{NaCl}$-salinity stress. Acta Physiologiae Plantarum, 30, 8189.
Khan, M., Iqbal, N., Masood, A. and Khan, N. (2012). Variation in salt tolerance of wheat cultivars: role of glycine betaine and ethylene. Pedosphere, 22, 746-754.

Mansour, M. (2000) Nitrogen containing compounds and adaptation of plants to salinity stress. Biologia Plantarum, 43, 491-500

Mohammed, A.R. and Tarpley, L. (2010) Effects of high night temperature and spikelet position on yield-related parameters of rice (Oryza sativa L.) plants. European Journal of Agronomy, 33, 117-123.

Morgan, J. (1980) Osmotic adjustment in the spikelets and leaves of wheat. Journal of Experimental Botany, 31, 655-665.

Nahar, K., Hasanuzzaman, M., Rahman, A., Alam, M.M., Mahmud, J.A., Suzuki, T. and Fujita, M. (2016) Polyamines confer salt tolerance in Mung Bean (Vigna radiata L.) by reducing sodium uptake, improving nutrient homeostasis, antioxidant defense, and methylglyoxal detoxification systems. Frontiers in Plant Science, 7, 1104. DOI: 10.3389/fpls.2016.01104

Nahar, K., Hasanuzzaman, M., Rahman, A., Alam, M.M., Mahmud, J.A., Suzuki, T. and Fujita, M. (2016) Polyamines confer salt tolerance in Mung Bean (Vigna radiata L.) by reducing sodium uptake, improving nutrient homeostasis, antioxidant defense, and methylglyoxal detoxification systems. Frontiers in Plant Science, 7, 1104. DOI: 10.3389/fpls.2016.01104

Puyang, X., An, M., Han, L. and Zhang, X. (2015) Protective effect of spermidine on salt stress induced oxidative damage in two Kentucky bluegrass (Poa pratensis L.) cultivars. Ecotoxicology and Environmental Safety, 117, 96-106.

Rohanipoor, A., Norouzi, M., Moezzi, A. and 
Hassibi, P. (2013) Effect of silicon on some physiological properties of maize (Zea mays) under salt Stress. Journal of Biological and Environmental Sciences, 7, 71-92.

Roychoudhury, A., Basu, S. and Sengupta, D.N. (2011) Amelioration of salinity stress by exogenously applied spermidine or spermine in three varieties of Indica rice differing in their level of salt tolerance. Journal of Plant Physiology, 168, 317-328.

Sang, T., Shan, X., Li, B., Shu, S., Sun, J. and Guo, S. (2016) Comparative proteomic analysis reveals the positive effect of exogenous spermidine on photosynthesis and salinity tolerance in cucumber seedlings. Plant Cell Reports, 35, 1769-1782.

Shi, J., Fu, X.Z., Peng, T., Huang, X.S., Fan, Q.J. and Liu, J.H. (2010) Spermine pretreatment confers dehydration tolerance of citrus in vitro plants via modulation of antioxidative capacity and stomatal response. Tree Physiology, 30, 914-922.

Sullivan, C.Y. and Ross, W. (1979) Selecting for drought and heat resistance in grain sorghum. Stress Physiology in Crop Plants, (eds H. Mussell and R. C. Staples), pp. 263-281. John Wiley and Sons, New York.

Zapata, P.J., Serrano, M., Pretel, M.T. and Botella, M.A. (2008) Changes in free polyamine concentration induced by salt stress in seedlings of different species. Plant Growth Regulation, 56, 167-177.

Zribi, L., Fatma, G., Fatma, R., Salwa, R., Hassan, N. and Néjib, R.M. (2009) Application of chlorophyll fluorescence for the diagnosis of salt stress in tomato "Solanum lycopersicum (variety Rio Grande)." Scientia Horticulturae, 120, 367-372.

\section{How to cite this article:}

Midathala Raghavendra, Dommalapati Sudhakara Rao, Shashi Madan and Renu Munjal. 2020. Physiological Role of Exogenous Spermine in Wheat (Triticum aestivum em. Thell) under Salinity. Int.J.Curr.Microbiol.App.Sci. 9(09): 999-1005. doi: https://doi.org/10.20546/ijcmas.2020.909.124 